ORIGINAL ARTICLE

\title{
Unflued gas heaters and respiratory symptoms in older people with asthma
}

\author{
P J Franklin, ${ }^{1,2} \mathrm{~J} \mathrm{Loveday,}^{1,2}$ A Cook ${ }^{1,2}$
}

\begin{abstract}
${ }^{1}$ School of Population Health, University of Western Australia, Perth, Western Australia,

Australia

${ }^{2}$ Cooperative Research Centre for Asthma and Airways, Glebe, New South Wales, Australia

\section{Correspondence to} Dr P Franklin, School of Population Health, University of Western Australia, 35 Stirling Highway, Perth, Western Australia 6009.

peter.franklin@uwa.edu.au
\end{abstract}

Received 22 March 2011 Accepted 21 December 2011 Published Online First 16 January 2012
ABSTRACT

Background Unflued gas heaters (UFGHs) and cookers are a major contributor to air pollution in homes. Gas appliances have been associated with adverse respiratory outcomes in children and, less consistently, adults. There have been very few studies on the effects of gas appliances on the respiratory health of older people. Objectives This study investigated the daily lung function and respiratory symptoms of older people (>55 years of age) who did and did not use an UFGH as a primary source of heating.

Methods 71 patients with asthma were recruited for the study. Each patient participated for one 12-week winter period. All patients recorded daytime and nighttime symptoms in a diary and completed morning and evening peak flow and forced expiratory volume in $1 \mathrm{~s}$ for the study period. General estimating equations were used to measure the associations between symptoms and lung function outcomes and same and previous day (lag 1) UFGH exposure.

Results Same and previous day (lag 1) UFGH exposure was associated with significantly increased ORs for wheeze and dyspnoea compared with days on which no heating was used. Furthermore, there were significant increases in the average odds of reported wheeze and dyspnoea per hour of UFGH heater use. Small but significant reductions in morning to evening peak flow and forced expiratory volume in $1 \mathrm{~s}$ were observed on the days an UFGH was used compared with days when other heating was used or there was no heating.

Conclusion Exposure to UFGHs may have a detrimental effect on symptoms and lung function in older people with mild to moderate asthma.

\section{INTRODUCTION}

Unflued gas cookers and heaters are a major source of nitrogen dioxide $\left(\mathrm{NO}_{2}\right)$, nitrous acid and carbon monoxide (CO) indoors. ${ }^{1}$ They can also emit formaldehyde and produce water vapour. ${ }^{2}$ In Australian homes combustion gases from unflued gas heaters (UFGHs), particularly $\mathrm{NO}_{2}$, can be significantly elevated during their operation, with peak concentrations reaching as high as $700 \mu \mathrm{g} / \mathrm{m}^{3} .{ }^{3}$ Although high peak $\mathrm{NO}_{2}$ concentrations can be obtained when using an unflued gas stove, ${ }^{4}$ UFGHs have been shown to be the major source of both indoor concentrations and personal exposure to $\mathrm{NO}_{2}$ in Perth, Western Australia, where the study was conducted. ${ }^{5}$

Exposure to gas appliances or indoor $\mathrm{NO}_{2}$ has been associated with an increase in respiratory symptoms in children and worsening of asthma in children and adults. ${ }^{6}$ The Institutes of Medicine
(US) recently concluded that $\mathrm{NO}_{2}$ is one of the few indoor pollutants for which there is sufficient evidence of a positive association between $\mathrm{NO}_{2}$ and asthma exacerbations. ${ }^{6}$ However, the findings remain inconsistent, ${ }^{7}$ and the Institutes of Medicine recommended future research to target population subgroups that are likely to be most exposed to determine the relationship between exposure of indoor $\mathrm{NO}_{2}$ and asthma. ${ }^{6}$

Older people, particularly those with existing cardio-respiratory diseases, may be more prone to the effects of air pollution than younger age groups. ${ }^{8}$ Few studies have addressed the adverse effects of indoor air pollution on respiratory health in older people. ${ }^{9}$ Some studies have, directly or indirectly, investigated the effect of either gas appliances ${ }^{10} 11$ or indoor $\mathrm{NO}_{2}{ }^{12}{ }^{13}$ on respiratory health in older age groups, but the results are conflicting. Older people, on average, spend more hours at home than other age groups (with the exception of infants), ${ }^{14}$ especially if they have a chronic illness. ${ }^{15}$ As ageing is associated with a decline in body thermoregulation and impaired peripheral temperature perception, ${ }^{16}$ older people have a greater need for heating during the winter. ${ }^{17}$ An increased need for heating in winter, combined with reduced home ventilation, can contribute to an accumulation of indoor pollutants, raising the risk of exposure to combustion products. ${ }^{9}$ The aim of the study was to investigate if using an UFGH during winter is detrimental to the respiratory health of older people with asthma.

\section{METHODS}

\section{Subjects and protocol}

Patients with asthma over 55 years of age were recruited from a patient database at the Lung Institute of Western Australia (LIWA). Apart from age, inclusion criteria were a history of physician-diagnosed asthma with evidence of symptoms in the past 12 months. Exclusion criteria were current smoking and the presence of respiratory comorbidities, such as doctor-diagnosed chronic obstructive pulmonary disease (COPD)

The study was conducted over two consecutive 12-week winter periods (2007 and 2008) but each patient only participated for one winter season. On recruitment, baseline lung function (spirometry) was measured and patients completed a questionnaire. During the 12 -week study period people were asked to complete a daily respiratory symptom diary in the morning and evening. Patients also recorded the use of heaters and cookers during each day. All patients were provided with an electronic lung 
function monitor to measure morning and evening lung function. Patients were visited every 2 weeks to collect and replace completed diaries. The study was approved by the University of Western Australia Human Research Ethics Committee.

\section{Techniques}

\section{Baseline lung function}

Baseline spirometry was measured, in accordance with the American Thoracic Society guidelines, ${ }^{18}$ in the patient's home using a portable spirometer (EasyOne Spirometer, ndd Medizintechnik AG, Zurich, Switzerland). Up to five measurements were collected to obtain at least two technically satisfactory manoeuvres. Quality grades of C or greater were accepted. Measurements were recorded for forced vital capacity, forced expiratory volume in $1 \mathrm{~s}\left(\mathrm{FEV}_{1}\right)$, peak flow (PEF) and midexpiratory flows $\left(\mathrm{FEF}_{25-75}\right)$. Data were downloaded using Easyware software (Easyware V.2.9, ndd Medizintechnik AG, Zurich, Switzerland). Predicted values were calculated using published reference values. ${ }^{19}$

\section{Baseline questionnaire}

Two questionnaires were completed by the patients on the first home visit. The first questionnaire asked about the home environment, including primary heating and cooking fuels, age of house, distance of home from busy roads, and presence of pets. ${ }^{20}$ The second questionnaire included questions on asthma severity (intermittent/mild or persistent), age at asthma diagnosis, seasonal asthma and medication. The questionnaire was based on severity criteria specified by the Australian National Asthma Council and has been used previously. ${ }^{21}$ Data on previous smoking patterns were also collected.

\section{Symptom diary}

Self-reported respiratory symptoms were recorded separately for each day and night on a 14-day diary. Patients were asked to indicate the presence and severity of symptoms on a scale of $0-3$, with $0=$ none, $1=$ mild, $2=$ moderate, $3=$ severe. Symptoms included wheeze, cough and dyspnoea. Patients completed the diary at night (for daytime symptoms) and on first rising in the morning (for night-time symptoms). Reliever medication usage was also recorded. Patients were asked to record if, and for how long, a heater or cooker was used when they were at home on each day. If patients had more than one type of heater they were asked to specify the type of heater that was used on a particular day.

\section{Daily lung function}

Patients were provided with an electronic lung function monitor (PiKo-1, Ferraris Cardiorespiratory Co, Louisville, Colorado, USA) to measure lung function first thing in the morning and before retiring in the evening. Patients were instructed to measure lung function prior to taking any asthma medication. The PiKo-1 measures $\mathrm{FEV}_{1}$ and PEF and has been compared favourably with the mini-Wright PEF metre. ${ }^{22}$ Patients were trained in using the monitors during the first home visit. At least three, and up to a total of five, measurements were collected in the morning and evening and recorded in the diary.

\section{Statistical analyses Baseline data}

Baseline lung function, age at the time of the study, age at first diagnosis of asthma and asthma severity parameters were compared among patients who used an UFGH as the primary heating source and those who had other heaters using Student t tests, Mann-Whitney $U$ tests and $\chi^{2}$ tests.

\section{Study data}

Symptom frequencies (wheeze, cough and dyspnoea) and mean $\mathrm{PEF}$ and $\mathrm{FEV}_{1}$ measurements across the entire study period were compared for the following exposure groups: days on which UFGHs were used versus days on which other forms of heating were used; days on which UFGHs were used versus days on which no heaters of any kind were used; and days on which other heaters were used versus days on which no heaters of any kind were used. Daily heater use was analysed as a dichotomous 'yes/no' variable for each measurement day. Relationships between daily hours of heater use and both symptoms and lung function were also investigated separately for UFGHs and other heaters. Same day and previous day (lag 1) analyses were conducted.

For symptom frequency, daytime and night-time symptoms were combined and the presence and severity were collapsed into dichotomous variables (none/mild and moderate/severe). The percentage of measurement days with symptoms was assessed for each patient. Use of asthma reliever medication (yes/no) on each measurement day was also assessed.

Lung function was assessed in two ways. First, as the daily difference, as a percentage, from the mean for each patient across the whole study period. This was analysed separately for morning and evening PEF and $\mathrm{FEV}_{1}$, although only the evening values were assessed for same day exposures. Second, changes from morning to evening for $\mathrm{PEF}$ and $\mathrm{FEV}_{1}$ were investigated using the following calculation:

$$
\text { (Morning PEF } / \mathrm{FEV}_{1} \text { - evening PEF/FEV }{ }_{1} \text { ) }
$$

$$
\text { /morning PEF/FEV } 1 \text { (\%) }
$$

Only same day exposures were assessed for morning to evening change. Analyses were also conducted for each patient to determine intra-individual variability of $\mathrm{FEV}_{1}$ and PEF over the study period. All lung function variables were normally distributed.

Generalised estimating equations (GEE) with an autoregression $\operatorname{AR}(1)$ (within-subject) correlation structure were used for advanced analysis. Analyses were conducted to investigate daily lung function and symptoms with daily heater use, as a dichotomous variable and reported hours of use. All GEE estimates were adjusted for other factors, including age and gender, use of gas cookers (yes/no), smoking in the home (yes/no), meteorological conditions and ambient $\mathrm{NO}_{2}$. Meteorological records for ambient daily temperatures and relative humidity, and outdoor $\mathrm{NO}_{2}$ concentrations were obtained for each study day from urban monitoring stations. Further, both calendar day and the relative day of the study were included in the models. For the GEE models, Gaussian models with identity link functions were used for percentage changes in $\mathrm{PEF}$ and $\mathrm{FEV}_{1}$ relative to the overall mean for each patient. This relative 'intra-individual' measure was used in preference to absolute lung function values, which can vary among patients because of differences in height, age and other attributes unrelated to the exposure of interest. For dichotomised outcomes binomial models with logit link functions were used to derive ORs. Missing and incomplete data were assessed for each patient. Residual analyses were conducted to identify outlying measurements. All statistical analyses were conducted with Stata/MP 10.0.

The study had at least $80 \%$ power (with type I error probability $\alpha=0.05$ ) to detect differences in risk estimates of symptoms with an OR of at least 1.30. For lung function measurements, the study had at least $80 \%$ power to detect 
Table 1 Baseline characteristics of patients

\begin{tabular}{|c|c|c|c|}
\hline Baseline characteristics & $\begin{array}{l}\text { UFGH } \\
(n=33)\end{array}$ & $\begin{array}{l}\text { Other heating } \\
(\mathrm{n}=38)\end{array}$ & p Value \\
\hline \multicolumn{4}{|l|}{ Demographics } \\
\hline $\operatorname{Sex}(F / M)$ & $18 / 15$ & $23 / 15$ & 0.641 \\
\hline Age (years) ${ }^{*}$ & $\begin{array}{l}70.0 \\
(64.0-71.0)\end{array}$ & $\begin{array}{l}67.5 \\
(66.0-76.0)\end{array}$ & 0.132 \\
\hline Occupation (prof/semi/trades)† & 19/6/7 & $21 / 11 / 4$ & 0.345 \\
\hline Socioeconomic Index* $\neq$ & $\begin{array}{l}83.0 \\
(61.0-91.5)\end{array}$ & $\begin{array}{l}81.0 \\
(67.5-94.0)\end{array}$ & 0.867 \\
\hline \multicolumn{4}{|l|}{ Baseline lung function measurements } \\
\hline$\%$ Pred FVC§ & $96.9(21.7)$ & $98.5(20.1)$ & 0.492 \\
\hline$\%$ Pred FEV $1 \S$ & $76.0(16.1)$ & $79.3(25.9)$ & 0.467 \\
\hline$\%$ FEV/FVC§ & $64.3(10.0)$ & $64.0(14.3)$ & 0.930 \\
\hline$\%$ Pred PEF§ & $87.1(22.3)$ & $90.7(26.0)$ & 0.383 \\
\hline \multicolumn{4}{|l|}{ Clinical parameters } \\
\hline $\begin{array}{l}\text { Asthma severity } \\
\text { (intermittent/persistent) }\end{array}$ & $17 / 159$ & $18 / 20$ & 0.301 \\
\hline Daily inhaled corticoid steroid use & $28 / 33(85 \%)$ & $34 / 38(90 \%)$ & 0.912 \\
\hline Ex-smokers & $17 / 33$ (53.1\%) & $15 / 37 \neq(46.9 \%)$ & 0.253 \\
\hline Age at asthma diagnosis (years) ${ }^{*}$ & $23.0(5.0-53.0)$ & $36.0(13.5-55.0)$ & 0.316 \\
\hline Seasonal asthma & $21 / 33(65.7 \%)$ & 19/38 (50.0\%) & 0.334 \\
\hline $\begin{array}{l}\text { Symptoms occurring primarily } \\
\text { in winter }\end{array}$ & $16 / 32(50 \%)$ & $13 / 35(37.1 \%)$ & 0.164 \\
\hline \multicolumn{4}{|c|}{$\begin{array}{l}\text { *Median (IOR). } \\
\text { †Prof, professional; semi, semi-professional; trades, tradesperson. } \\
\text { †Index of socio-economic disadvantage based on residential address. } \\
\text { SMean (SD). } \\
\text { ॠMissing data point. } \\
\text { UFGH, unflued gas heater; FEV } 1 \text {, forced expiratory volume in } 1 \mathrm{~s} \text {; FVC, forced vital capacity; } \\
\text { PEF, peak expiratory flow; Pred, predicted. }\end{array}$} \\
\hline
\end{tabular}

differences of $2.8 \%$ change from the average subject measurement in the exposed (UFGH) group for PEF, and $4 \%$ change from the average subject measurement in the exposed (UFGH) group for $\mathrm{FEV}_{1}$ (with type I error probability $\alpha=0.05$ ).

\section{RESULTS}

\section{Baseline data}

Seventy-seven patients were recruited into the study. Two patients were excluded due to comorbidities and four withdrew because they could not complete the requirements of the study. A full set of data were analysed for 71 patients. All patients were Caucasian with similar socioeconomic backgrounds, as determined by last or current occupation and residential address (table 1). Thirty-three (46.5\%) patients used UFGHs as their primary source of heating. Primary heating fuel for the 'other' group included electricity $(n=23)$, flued gas $(n=9)$, oil $(n=2)$, closed wood heater $(n=2)$ and open fireplace $(n=1)$. One patient did not use any heating. Flued gas was included in the 'other' group as this has previously been shown not to increase indoor $\mathrm{NO}_{2}$ concentrations. ${ }^{6}$ There were no significant differences between the two groups with regards to age at time of study,
Table 2 Symptom frequency (\%) and lung function on days with and without heating

\begin{tabular}{|c|c|c|c|}
\hline & $\begin{array}{l}\text { Days UFGH } \\
\text { used } \\
(n=1713 \text { days })\end{array}$ & $\begin{array}{l}\text { Days other } \\
\text { heater used } \\
\text { ( } n=2421 \text { days) }\end{array}$ & $\begin{array}{l}\text { Days no } \\
\text { heating used } \\
(\mathrm{n}=1388 \text { days })\end{array}$ \\
\hline \multicolumn{4}{|l|}{ Symptoms* } \\
\hline Wheeze & $13.4(2.2-37.5)$ & $10.4(0.0-43.2)$ & $0.5(0.0-27.1)$ \\
\hline Cough & $0.0(0.0-3.4)$ & $0.0(0.0-3.2)$ & $0.0(0.0-1.6)$ \\
\hline Dyspnoea & $0.0(0.0-2.1)$ & $0.0(0.0-4.2)$ & $0.0(0.0-0.6)$ \\
\hline \multicolumn{4}{|l|}{ Lung function† } \\
\hline $\begin{array}{l}\text { morning PEF } \\
\text { (litres/min) }\end{array}$ & $310(111)$ & $297(100)$ & $296(102)$ \\
\hline $\begin{array}{l}\text { evening PEF } \\
\text { (litres/min) }\end{array}$ & 313 (107) & $298(95)$ & $305(103)$ \\
\hline $\begin{array}{l}\text { morning-evening } \\
\text { change PEF (\%) }\end{array}$ & $1.86(5.73)$ & $2.36(6.55)$ & $3.66(6.25)$ \\
\hline $\begin{array}{l}\text { morning FEV } \\
\text { (litres) }\end{array}$ & $1.90(0.57)$ & $1.83(0.60)$ & $1.86(0.58)$ \\
\hline $\begin{array}{l}\text { evening FEV }{ }_{1} \\
\text { (litres) }\end{array}$ & $1.90(0.55)$ & $1.82(0.59)$ & $1.86(0.59)$ \\
\hline $\begin{array}{l}\text { morning-evening } \\
\text { change } \mathrm{FEV}_{1}(\%)\end{array}$ & $0.63(5.53)$ & $0.67(8.26)$ & $2.44(6.32)$ \\
\hline
\end{tabular}

age at asthma diagnosis, past smoking, daily inhaled corticoid steroid use and asthma severity (table 1).

There was no difference in ambient conditions on days the different heaters were used. There were also no differences in the patterns of usage for the different types of heaters. UFGHs were used on $64 \%$ of days and other heaters were used on $67 \%$ of days. The daily average (SD) number of hours of heater use on those days was 5.3 (1.9) $\mathrm{h}$ and 5.4 (0.3) h, respectively.

\section{Symptoms}

Symptom frequencies for the study period are presented in table 2. Using the fully adjusted GEE model, positive associations were observed between a number of symptoms and UFGH use (table 3). ORs were significantly elevated comparing UFGH days with days on which no heaters were used for wheeze (same day and lag 1), cough (lag 1) and dyspnoea (same day and lag 1). There was no effect on reliever medication usage. The odds of dyspnoea were significantly elevated with the use of other heaters compared with no heating at lag 1 (table 3 ).

ORs for wheeze (same day and lag 1) and dyspnoea (same day and lag 1) for hours of heater use were elevated for UFGH users but not other heater users (table 4).

\section{Lung function}

Raw lung function variables for the different heaters used are presented in table 2 . In the fully adjusted GEE model there were

Table 3 Adjusted ORs (95\% Cl) of symptom occurrence usage by heater type

\begin{tabular}{|c|c|c|c|c|c|c|}
\hline & \multicolumn{2}{|l|}{ Wheeze } & \multicolumn{2}{|l|}{ Cough } & \multicolumn{2}{|l|}{ Dyspnoea } \\
\hline & Same day & $\operatorname{Lag} 1$ & Same day & $\operatorname{Lag} 1$ & Same day & $\operatorname{Lag} 1$ \\
\hline $\begin{array}{l}\text { UFGH versus other heater used } \\
\text { ( } n=1713 \text { vs } 2421 \text { days) }\end{array}$ & 1.21 (0.99 to 1.48$)$ & $1.22(1.00 \text { to } 1.50)^{*}$ & $0.77(0.53$ to 1.11$)$ & $0.79(0.54$ to 1.15$)$ & $0.78(0.56$ to 1.09$)$ & $0.79(0.56$ to 1.12$)$ \\
\hline $\begin{array}{l}\text { UFGH used versus no heating } \\
\text { ( } n=1713 \text { vs } 1388 \text { days) }\end{array}$ & $1.25(1.05 \text { to } 1.50)^{*}$ & $1.22(1.01 \text { to } 1.48)^{*}$ & $1.38(0.91$ to 2.09$)$ & $1.55(1.00 \text { to } 2.40)^{*}$ & $1.87(1.30 \text { to } 2.70)^{*}$ & $2.05(1.41 \text { to } 2.99)^{*}$ \\
\hline $\begin{array}{l}\text { Other heater used versus no heating } \\
\text { ( } n=2421 \text { vs } 1388 \text { days) }\end{array}$ & 1.01 (0.88 to 1.17$)$ & $1.03(0.89$ to 1.20$)$ & 1.15 (0.83 to 1.59$)$ & $1.21(0.85$ to 1.71$)$ & $1.40(0.99$ to 2.00$)$ & $1.56(1.07 \text { to } 2.28)^{*}$ \\
\hline
\end{tabular}

Adjusted for age, gender, exposure to tobacco smoke, exposure to cooking gas, ambient temperature, humidity and external $\mathrm{NO}_{2}$ levels.

* Significant finding $(\mathrm{p}<0.05)$.

UFGH, unflued gas heater. 
Table 4 Adjusted ORs (95\% Cl) of symptom occurrence per hour of use for heater type

\begin{tabular}{|c|c|c|c|c|c|c|}
\hline & \multicolumn{2}{|l|}{ Wheeze } & \multicolumn{2}{|l|}{ Cough } & \multicolumn{2}{|l|}{ Dyspnoea } \\
\hline & Same day & Lag 1 & Same day & $\operatorname{Lag} 1$ & Same day & $\operatorname{Lag} 1$ \\
\hline $\begin{array}{l}\text { Hours of UFGH use ( } n=33 \text { patients; } \\
1713 \text { days) }\end{array}$ & $1.05(1.02 \text { to } 1.08)^{*}$ & $1.05(1.02 \text { to } 1.08)^{*}$ & 0.97 (0.90 to 1.04$)$ & $0.97(0.90$ to 1.05$)$ & $1.07(1.02 \text { to } 1.13)^{*}$ & $1.07(1.02 \text { to } 1.13)^{*}$ \\
\hline
\end{tabular}

Adjusted for age, gender, exposure to tobacco smoke, exposure to cooking gas, ambient temperature, humidity and external $\mathrm{NO}_{2}$ levels.

*Significant finding $(\mathrm{p}<0.05)$.

UFGH, unflued gas heater.

no declines in PEF or $\mathrm{FEV}_{1}$ (morning or evening) relative to the subject mean for same day or lag 1 UFGH use (table 5). However, when analysing exposure by hours of use there were small but significant percentage declines, relative to the subject mean, for morning PEF $(-0.24 \%$ per hour of use, -0.41 to $-0.07)$ and $\mathrm{FEV}_{1}(-0.21,-0.38$ to -0.03$)$ for previous day UFGH use (table 6).

There was a significant decrease in the morning to evening changes in PEF and FEV 1 when UFGHs were used compared with other heater use and no heater use (table 5).

\section{Missing data}

Patterns of the missing and incomplete data were assessed to determine if there was any consistent pattern of absent results. One patient did not undertake lung function but completed all the other components; two others omitted $\sim 20 \%$ of their lung function measurements. Sensitivity analysis was repeated with these patients excluded. No major shift in risk estimates was observed subsequent to their exclusion. Apart from these patients, data were missing completely at random, and hence were left missing.

\section{DISCUSSION}

There are very few data on the effects of heating sources on the symptoms of older people with pre-existing respiratory disease. The use of UFGHs is considered a risk for symptoms in children with asthma, ${ }^{6}$ but older people are a group that may experience an even greater exposure to these heaters due to increased need for heating ${ }^{17}$ and more time spent indoors. ${ }^{14}$ In this study we found that UFGH use was associated with increased symptoms and small changes in lung function in older people with asthma. There was also evidence of an exposure-response relationship between UFGH use and both lung function and respiratory symptoms. These findings are suggestive of an adverse effect of UFGH in older people with existing respiratory illness.

There is a large body of literature on the adverse impacts of UFG appliances and/or indoor $\mathrm{NO}_{2}$ on the health of residents, ${ }^{6}$ mostly children. The evidence to date is considered to be suggestive of a causal relationship between the worsening of asthma symptoms and increased respiratory symptoms in children. ${ }^{6}$ The evidence for adults is less consistent. ${ }^{7}$ Previous studies with adults have focused on the use of gas stoves. ${ }^{723-26}$ This study investigated UFGH use because this is the major predictor of concentrations of $\mathrm{NO}_{2}$ in homes where the study was conducted. ${ }^{5}$

In this study we observed an association between UFGH use and wheeze, cough and dyspnoea. Furthermore, there were increased odds for reported wheeze and dyspnoea with increasing hours of UFGH use. Increased wheeze, cough and dyspnoea are commonly reported respiratory problems in previous studies, ${ }^{25} 2728$ although associations are not consistent. ${ }^{23}$ A few cross-sectional studies have assessed respiratory symptoms and exposure to gas appliances in older people but the results are also conflicting. ${ }^{10-13}$ Only two other panel studies have investigated relationships between indoor $\mathrm{NO}_{2}{ }^{29}$ or gas appliances ${ }^{30}$ and daily respiratory symptoms in adults with asthma. Smith et al ${ }^{29}$ reported associations between personal concentrations of $\mathrm{NO}_{2}$ and symptoms in children with asthma but not in adults over the age of 50 years. Ostro et $a l^{30}$ found an association between reported use of gas stoves and moderate to severe wheeze and cough in adults with asthma aged between 18 and 70 years. There was no stratification by age and therefore it is difficult to determine if older adults were more susceptible than younger adults. ${ }^{30}$

The increased odds of symptoms with UFGH use were observed mostly when compared with no heater use, although wheeze was also increased when compared with other heater use. There was evidence that any (UFGH and other) heater use was associated with increased dyspnoea and, therefore, other factors, such as indoor temperature, may be important. However, for wheeze and dyspnoea an exposure response with hours of UFGH, but not other heater use, was evident, suggesting that emissions from these heaters may be important. Emissions of combustion pollutants from UFGHs can remain high during the operation of the appliance. ${ }^{3}$ Heater use and

Table 5 Adjusted relative percentage changes (95\% CI), relative to subject mean, in PEF and $\mathrm{FEV}_{1}$ by heater type

\begin{tabular}{|c|c|c|c|c|}
\hline & \multicolumn{2}{|l|}{ Same day } & \multicolumn{2}{|l|}{ Lag 1} \\
\hline & Evening & Change morning-evening & Morning & Evening \\
\hline \multicolumn{5}{|l|}{ PEF } \\
\hline Days UFGH used versus no heating & $-0.50(-1.39$ to 0.38$)$ & $-2.53(-3.58 \text { to }-1.49)^{*}$ & $-0.22(-1.13$ to 0.68$)$ & $0.14(-0.77$ to 1.06$)$ \\
\hline Days other heater used versus no heating & $-1.21(-1.79$ to 0.45$)$ & $-0.78(-1.76$ to 0.20$)$ & $-0.38(-1.16$ to 0.41$)$ & $0.08(-0.69$ to 0.85$)$ \\
\hline \multicolumn{5}{|l|}{$\mathrm{FEV}_{1}$} \\
\hline Days other heater used versus no heating & $-1.14(-2.04$ to 0.24$)$ & $0.84(-1.90$ to 0.22$)$ & $-0.27(-1.20$ to 0.65$)$ & $-0.18(-1.09$ to 0.73$)$ \\
\hline
\end{tabular}

Adjusted for age, gender, exposure to tobacco smoke, exposure to cooking gas, ambient temperature, humidity and external $\mathrm{NO}_{2}$ levels.

*Significant finding $(\mathrm{p}<0.05)$.

UFGH, unflued gas heater; FEV $_{1}$, forced expiratory volume in $1 \mathrm{~s}$; PEF, peak expiratory flow. 
Table 6 Percentage $(95 \% \mathrm{Cl})$ lung function changes per hour of heater use

\begin{tabular}{|c|c|c|c|c|}
\hline & \multicolumn{2}{|l|}{ Same day } & \multicolumn{2}{|l|}{ Lag 1} \\
\hline & Evening & Change morning-evening & Morning & Evening \\
\hline \multicolumn{5}{|l|}{ PEF } \\
\hline Hours of other heater use ( $n=38$ patients) & $0.0(-0.10$ to 0.11$)$ & $0.00(-0.13$ to 0.14$)$ & $-0.02(-0.13$ to 0.09$)$ & $0.02(-0.08$ to 0.12$)$ \\
\hline \multicolumn{5}{|l|}{$\mathrm{FEV}_{1}$} \\
\hline Hours of UFGH use ( $n=33$ patients) & $-0.06(-0.23$ to 0.11$)$ & $-0.05(-0.26$ to 0.16$)$ & $-0.21(-0.38 \text { to }-0.03)^{*}$ & $0.03(-0.14$ to 0.20$)$ \\
\hline
\end{tabular}

Adjusted for age, gender, exposure to tobacco smoke, exposure to cooking gas, ambient temperature, humidity and external $\mathrm{NO}_{2}$ levels.

* Significant finding $(p<0.05)$.

UFGH, unflued gas heater; $\mathrm{FEV}_{1}$, forced expiratory volume in $1 \mathrm{~s}$; PEF, peak expiratory flow.

symptoms were recorded in the same diary and it is possible that this may lead to a reporting bias. However, if people were aware of the health effects of using UFGHs they would be less likely to use this type of heating.

In this study there were small but significant decreases in lung function associated with UFGH use. This included a decrease in the morning to evening change in PEF and $\mathrm{FEV}_{1}$ on the days that UFGHs were used compared with days when other heaters were used or there was no heating. There were also small decrements in morning lung function ( $\mathrm{PEF}$ and $\mathrm{FEV}_{1}$ ) associated with increasing hours of UFGH use but not with increasing hours of other heater use. Data on the effect of $\mathrm{NO}_{2}$ on lung function are inconsistent. Some epidemiological studies have reported small but significant decrements in lung function associated with exposure to $\mathrm{NO}_{2}{ }^{26}$ or gas appliances, ${ }^{23}{ }^{24}$ whereas others have found no association. ${ }^{23}$ The findings of an across day change in lung function when using an UFGH may be analogous to a cross-shift effect. To some degree the results are consistent with a study by $\mathrm{Ng}$ et al, ${ }^{26}$ who reported a decrease in PEF $(3.4 \%)$ in non-smoking women with asthma after cooking on a gas stove. However, that study ${ }^{26}$ found an actual decrease in lung function, while we observed a reduced increase in morning to evening lung function when compared with no heater and other heater use.

As with respiratory symptoms, we observed a dose-response relationship between lung function and hours of UFGH use, but not other heater use. Morning PEF and $\mathrm{FEV}_{1}$ decreased with increasing hours of UFGH use on the previous day. $\mathrm{Ng}$ et al ${ }^{26}$ also reported an association between increasing $\mathrm{NO}_{2}$ levels during cooking and the post-cooking fall in PEF. An exposureresponse relationship may indicate a real, albeit small, effect. As this was not evident with other heater use it is more likely to be related to combustion gases rather than indoor temperature. We did not have data on indoor $\mathrm{NO}_{2}$ or temperature to investigate this further.

Patients in this study generally had mild to moderate symptoms and were still reasonably active. None of the patients were confined to their homes because of the severity of their disease. The effects of UFG appliances on older people with more severe symptoms or who are less mobile will be important to determine if this modifiable risk factor contributes to ongoing respiratory morbidity in older people.

Acknowledgements The authors would first and foremost like to acknowledge all the patients who participated in the study. We would also like to acknowledge the Lung Institute of Western Australia (LIWA) where we were able to identify the patients. The study was funded by the CRC for Asthma and Airways.

Funding Australian Government research funding

Competing interests None.

Ethics approval Ethics approval was provided by University of Western Australia Human Research Ethics Committee.
Contributors PF designed the study, helped in recruitment and data collection and was the principal author of the manuscript. He is guarantor. JL undertook most of the recruitment and data collection and cleaning, and contributed to the drafting of the paper. AC undertook most of the analyses, wrote the statistical analysis section of the manuscript and contributed to the drafting of the paper.

Provenance and peer review Not commissioned; externally peer reviewed.

\section{REFERENCES}

1. Lee K, Xue J, Geyh AS, et al. Nitrous acid, nitrogen dioxide, and ozone concentrations in residential environments. Environ Health Perspect 2002;110:145-50.

2. Brown SK, Mahoney KJ, Cheng M. Room chamber assessment of the pollutant emission properties of (nominally) low-emission unflued gas heaters. Indoor Air 2004;14(Suppl 8):84-91.

3. Department of Environment and Heritage. Unflued Gas Appliances and Air Quality in Australian Homes. Canberra: Department of Environment and Heritage, 2004.

4. Goldstein BD, Melia RJ, Chinn S, et al. The relation between respiratory illness in primary schoolchildren and the use of gas for cooking-II. Factors affecting nitrogen dioxide levels in the home. Int J Epidemiol 1979;8:339-45.

5. Farrer D, Runnion $C$, Dingle $P$, et al. The effect of unflued gas heaters on residential nitrogen dioxide concentrations in Perth, Western Australia. Clean Air Environ Qual $\mathrm{J}$ 2005:39:46-50.

6. Institute of Medicine. Clearing the Air: Asthma and Indoor Air Exposures. Washington DC: National Academy Press, 2000.

7. Basu R, Samet JM. A review of the epidemiological evidence on health effects of nitrogen dioxide exposure from gas stoves. J Environ Med 1999;1:173-87.

8. Annesi-Maesano I, Agabiti N, Pistelli R, et al. Subpopulations at increased risk of adverse health outcomes from air pollution. Eur Respir J 2003:40:57s-63s.

9. Coelho C, Steers M, Lutzler P, et al. Indoor air pollution in old people's homes related to some health problems: a survey study. Indoor Air 2005;15:267-74.

10. Dow L, Phelps L, Fowler L, et al. Respiratory symptoms in older people and use of domestic gas appliances. Thorax 1999;54:1104-6.

11. Jedrychowski W, Tobiasz-Adamczyk B, Flak $E$, et al. Effect of indoor air pollution caused by domestic cooking on respiratory problems of elderly women. Environ Int 1990; 16:57-60.

12. Osman LM, Douglas JG, Garden C, et al. Indoor air quality in homes of patients with chronic obstructive pulmonary disease. Am J Respir Crit Care Med 2007:176:465-72.

13. Simoni M, Carrozzi L, Baldacci S, et al. The Po River Delta (north Italy) indoor epidemiological study: effects of pollutant exposure on acute respiratory symptoms and respiratory function in adults. Arch Environ Health 2002;57:130-6.

14. Brasche $\mathbf{S}$, Bischof W. Daily time spent indoors in German homes-baseline data for the assessment of indoor exposure of German occupants. Int J Hyg Environ Health 2005:208:247-53.

15. Leech JA, Smith-Doiron M. Exposure time and place: do COPD patients differ from the general population? J Expo Sci Environ Epidemiol 2006;16:238-41.

16. Collins KJ, Exton-Smith AN, Dore C. Urban hypothermia: preferred temperature and thermal perception in old age. Br Med J (Clin Res Ed) 1981;282:175-7.

17. Morgan R, Blair A, King D. A winter survey of domestic heating among elderly patients. J R Soc Med 1996;89:85-6.

18. Miller MR, Hankinson J, Brusasco V, et al. Standardisation of spirometry. Eur Respir J 2005;26:319-38.

19. Hankinson JL, Odencrantz JR, Fedan KB. Spirometric reference values from a sample of the general US population. Am J Respir Crit Care Med 1999:159:179-87.

20. Lebowitz MD, Quackenboss JJ, Kollander M, et al. The new standard environmental inventory questionnaire for estimation of indoor concentrations. JAPCA 1989:39:1411-19.

21. Kedda M-A, Duffy DL, Bradley B, et al. ADAM33 haplotypes are associated with asthma in a large Australian population. Eur J Hum Genet 2006;14:1027-36.

22. Fonseca JA, Costa-Pereira A, Delgado $L$, et al. Pulmonary function electronic monitoring devices: a randomized agreement study. Chest 2005;128:1258-65. 
23. Eisner MD, Blanc PD. Gas stove use and respiratory health among adults with asthma in NHANES III. Occup Environ Med 2003;60:759-64.

24. Jarvis $\mathbf{D}$, Chinn $\mathrm{S}$, Sterne J, et al. The association of respiratory symptoms and lung function with the use of gas for cooking. European Community Respiratory Health Survey. Eur Respir J 1998;11:651-8.

25. Kerkhof M, de Monchy JG, Rijken B, et al. The effect of gas cooking on bronchial hyperresponsiveness and the role of immunoglobulin E. Eur Respir $J$ 1999;14:839-44.

26. $\mathbf{N g}$ TP, Seet CS, Tan WC, et al. Nitrogen dioxide exposure from domestic gas cooking and airway response in asthmatic women. Thorax 2001;56:596-601.
27. Jarvis $\mathbf{D}$, Chinn $\mathrm{S}$, Luczynska $\mathrm{C}$, et al. Association of respiratory symptoms and lung function in young adults with use of domestic gas appliances. Lancet 1996; 347:426-31.

28. $\mathbf{N g ~ T P}$, Hui KP, Tan WC. Respiratory symptoms and lung function effects of domestic exposure to tobacco smoke and cooking by gas in non-smoking women in Singapore. J Epidemiol Community Health 1993:47:454-8.

29. Smith BJ, Nitschke M, Pilotto LS, et al. Health effects of daily indoor nitrogen dioxide exposure in people with asthma. Eur Respir J 2000;16:879-85.

30. Ostro BD, Lipsett MJ, Mann JK, et al. Indoor air pollution and asthma. Results from a panel study. Am J Respir Crit Care Med 1994;149:1400-6.
Advancing Postgraduates. Enhancing Healthcare.

The Postgraduate Medical Journal is dedicated to advancing the understanding of postgraduate medical education and training.

- Acquire the necessary skills to deliver the highest possible standards of patient care

- Develop suitable training programmes for your trainees

- Maintain high standards after training ends

Published on behalf of the fellowship for Postgraduate Medicine

FOR MORE DETAILS OR TO SUBSCRIBE, VISIT THE WEBSITE TODAY

postgradmedj.com 